\title{
Respiratory infections and their influence on lung function in children: a multiple regression analysis
}

\author{
JWG YARNELL, AS ST LEGER \\ From the Medical Research Council Epidemiology Unit, Cardiff
}

\begin{abstract}
The relationship between a history of respiratory infections (and associated variables) in children and lung function in later life was examined in a study among 2228 children aged 7 to 11 years. In a multiple regression analysis only a few variables showed marked and consistent effects on lung function. Respiratory tract infections showed increasing impairment of lung function with repeated infections, but the impairment was smaller than that caused by current asthma.
\end{abstract}

Frequent respiratory infections are a common occurrence in infancy and childhood but several investigators $^{1-3}$ have attempted to define groups at special risk of developing chronic obstructive airways disease in later life. In the present report data from a representative sample of children from South Wales and the West of England is used to examine the effect on lung function of reported past history of respiratory infections and present symptoms.

\section{Methods}

The study sample comprises 2228 schoolchildren aged 7 to 11 years from South Wales and the West of England. A complete description of the study sample, questionnaire, and clinical measurements is to be found in the accompanying paper. ${ }^{4}$

All values for the lung function indices forced expiratory volume in 0.75 second $\left(\mathrm{FEV}_{0.75}\right)$ and forced vital capacity were adjusted for height (to a standard height of $130 \mathrm{~cm}$ ) as described previously. ${ }^{4}$ Adjusted values have been termed $F E_{0.75} \mathrm{I}$ and FVC I respectively. Multiple regression analysis was performed separately on the three dependent variables $\mathrm{FEV}_{0.75} \mathrm{I}$, FVCI, and $\mathrm{FEV}_{\mathbf{0}} \mathrm{.75}_{\mathrm{FVC}} \mathrm{FV}_{\text {ratio. In }}$ each case the set of independent variables included both quantitative variables (for example, average daily number of cigarettes smoked by mother during pregnancy) and qualitative variables (for example, sex). Quantitative variables are each associated with a regression "slope" coefficient whereas qualitative variables, which are also sometimes called factors, are associated with a

Address for reprint requests: Dr JWG Yarnell, MRC Epidemiology Unit, 4 Richmond Road, Cardiff CF2 3AS. separate "intercept" for each group defined by the variable. The full regression model consisted of these variables and their interactions with the sex factor. The presence of an interaction between sex and a quantitative variable entails having a separate slope coefficient for that variable in both sexes. Similarly a sex interaction with a factor means that the model requires a separate intercept coefficient in each sex for every group defined by the factor. For example the qualitative variable "area" defines the average lung function index value to be found in each of five geographical areas. The model, when fitted, may show that this average differs markedly between areas and the presence of a sex interaction implies that this average differs between areas between sexes or in other words the sex difference is not the same in every area. Interaction terms were excluded from the model if their presence did not contribute sufficiently to the overall fit of the model. That is, for each lung function measure, the simplest adequate model was selected. In the sequel where we write about the "effect" of a variable, as derived from the regression coefficient, we are only using this term as a shorthand for "the statistical association between the variable and the lung function index" and we are not implying that a cause and effect relationship exists.

The model selected for $\mathrm{FEV}_{0.75} \mathrm{I}$ accounted for $8 \%$ of the variation in $\mathrm{FEV}_{\mathbf{0}}{ }_{75} \mathrm{I}$ and no interaction terms were necessary. For FVC I it was necessary to include interactions between sex and "area of residence" and between sex and "history of chronic respiratory disease" and this model accounted for $15 \%$ of the variation. No interaction was needed for $\mathrm{FEV}_{0.75} / \mathrm{FVC}$ ratio and $10 \%$ of the variation was explained.

The number of subjects included in the regression 
Independent
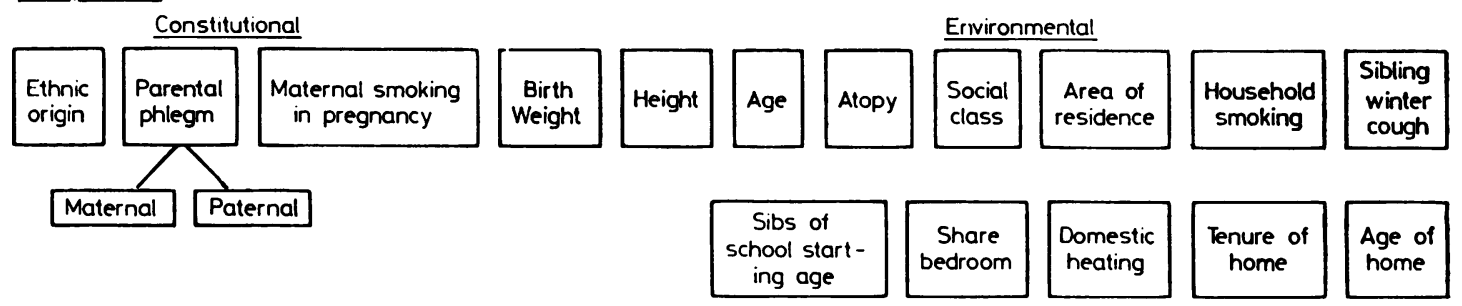

Dependent Objective measurements

History and symptoms
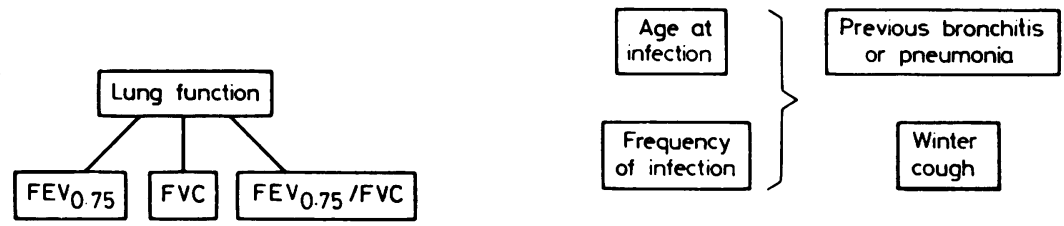

Figure ractors affecting lung function in children: main study variables.

analyses does not tally exactly with the number in the tables because regression analysis was only performed with the set of subjects for whom there was information recorded on all the independent variables.

Variables selected for inclusion in the multiple regression analysis were chosen after detailed consideration of the initial contingency tables. The following variables were incorporated: (1) area of residence-South Wales: urban 1 and 2, rural; Avon: urban, rural; (2) sex: male, female; (3) bronchitis/pneumonia: frequency of infection; (4) maternal phlegm: yes, no; (5) paternal phlegm: yes, no; (6) smoking in pregnancy; (7) household smoking; (8) history of asthma, hay fever, eczema; (9) age at first respiratory infection.

\section{Results}

In all, 2305 children were eligible for inclusion in the study; $2228(97 \%)$ children were seen at the schools and had the appropriate measurements made; $2132(92 \%)$ parents each completed the majority of the questionnaire. In approximately one-third of cases in which an incomplete questionnaire was returned this was because the child had been adopted.

The figure summarises the main study variables

Table 1 Mean values and (SD) of lung function indices by selected variables

\begin{tabular}{|c|c|c|c|c|c|c|c|c|c|}
\hline \multirow[t]{2}{*}{ Variables } & \multicolumn{2}{|c|}{ Number } & \multicolumn{2}{|c|}{$F E V_{0.75}$ index $^{\mathrm{a}}$ litres } & \multicolumn{2}{|c|}{ FVC index $^{\mathrm{a}} \quad$ litres } & \multicolumn{3}{|c|}{$F E V_{0.75} / F V C \times 100$} \\
\hline & Boys & Girls & Boys & Girls & Boys & Girls & Boys & & Girls \\
\hline \multicolumn{10}{|l|}{ Ethnic origins } \\
\hline Caucasian & 1028 & 1052 & $1.73(0 \cdot 19)$ & $1.66(0.21)$ & $1.99(0.36)$ & $1.92(0.41)$ & 864 & $(7 \cdot 0)$ & $89 \cdot 8(6 \cdot 2)$ \\
\hline African & 41 & 43 & $1.58(0.21)$ & $1.53(0.21)$ & $1.84(0.37)$ & $1 \cdot 82(0 \cdot 35)$ & $88 \cdot 6$ & $(6.9)$ & $89.7(5.5)$ \\
\hline Asian & 30 & 25 & $1 \cdot 55(0 \cdot 18)$ & $1.61(0.21)$ & $1 \cdot 74(0 \cdot 35)$ & $183(0.43)$ & $89 \cdot 4$ & $(7 \cdot 6)$ & $93.0(4.9)$ \\
\hline \multicolumn{10}{|l|}{ 'Atopy } \\
\hline Asthma in past 12 months & 35 & 15 & $1.60(0.23)$ & $1.44(0.35)$ & $2 \cdot 02(0 \cdot 34)$ & $1.65(0.33)$ & $79 \cdot 2$ & $(10 \cdot 0)$ & $85 \cdot 8(9 \cdot 2)$ \\
\hline Previous history asthma & 38 & 15 & $1.68(0.24)$ & $1 \cdot 61(0 \cdot 19)$ & $1.94(0.28)$ & $1.77(0.29)$ & $85 \cdot 2$ & $(6 \cdot 5)$ & $91 \cdot 1(7 \cdot 6)$ \\
\hline Current hay fever & 55 & 48 & $1 \cdot 70(0 \cdot 19)$ & $1.66(0.18)$ & $1.97(0.23)$ & $1.82(0 \cdot 17)$ & $85 \cdot 7$ & $(7 \cdot 6)$ & $89 \cdot 5(6 \cdot 3)$ \\
\hline Previous hay fever & 81 & 70 & $1 \cdot 73(0 \cdot 20)$ & $1.62(0 \cdot 20)$ & $2.00(0.21)$ & $1 \cdot 78(0 \cdot 19)$ & $85 \cdot 4$ & $(6 \cdot 7)$ & $89.4(6.6)$ \\
\hline No history of atopy & 788 & 880 & $1 \cdot 74(0 \cdot 19)$ & $1 \cdot 67(0 \cdot 20)$ & $1.99(0.22)$ & $1.84(0.22)$ & 86.9 & $(6 \cdot 7)$ & $89 \cdot 8(6 \cdot 1)$ \\
\hline NR of NK & 31 & 24 & $1 \cdot 77(0 \cdot 21)$ & $1.66(0.27)$ & $2.04(0.21)$ & $1 \cdot 76(0.31)$ & $86 \cdot 3$ & $(7 \cdot 1)$ & $93 \cdot 5(4 \cdot 7)$ \\
\hline \multicolumn{10}{|l|}{ bPrevious bronchitis } \\
\hline None & 776 & 841 & $1 \cdot 74(0 \cdot 19)$ & $1 \cdot 67(0 \cdot 20)$ & $1.98(0 \cdot 22)$ & $1.84(0 \cdot 22)$ & $87 \cdot 0$ & $(6 \cdot 7)$ & $90 \cdot 0(6 \cdot 1)$ \\
\hline One attack & 88 & 76 & $1 \cdot 73(0 \cdot 19)$ & $1.63(0 \cdot 20)$ & $1.98(0.23)$ & $1 \cdot 81(0 \cdot 21)$ & $86 \cdot 8$ & $(6 \cdot 9)$ & $89 \cdot 2(6.9)$ \\
\hline Five or more attacks & 55 & 29 & $1.61(0 \cdot 21)$ & $1.57(0 \cdot 19)$ & $2 \cdot 01(0 \cdot 27)$ & $1 \cdot 76(0 \cdot 23)$ & $83 \cdot 0$ & $(7 \cdot 3)$ & $88 \cdot 3(5 \cdot 5)$ \\
\hline \multicolumn{10}{|l|}{ bWinter cough } \\
\hline None & 727 & 767 & $1 \cdot 74(0 \cdot 19)$ & $1 \cdot 67(0 \cdot 19)$ & $1.99(0.22)$ & $1.84(0.21)$ & $86 \cdot 6$ & $(6 \cdot 8)$ & $89 \cdot 8(6 \cdot 1)$ \\
\hline Positive & 254 & 250 & $1 \cdot 71(0 \cdot 20)$ & $1.63(0.23)$ & $1.98(0.23)$ & $1.81(0.25)$ & $85 \cdot 8$ & $(7 \cdot 7)$ & $89.3(6.7)$ \\
\hline NR or NK & 47 & 35 & $1 \cdot 74(0 \cdot 19)$ & $1.68(0.23)$ & $2.01(0.21)$ & $1.79(0.28)$ & $86 \cdot 2$ & $(7 \cdot 0)$ & $90.0(6.0)$ \\
\hline
\end{tabular}

adjusted to a standard height of $1300 \mathrm{~mm}$.

bCaucasian children only. 
Table 2 Mean values and (SD) of lung function indices by previous history of bronchitis or pneumonia

\begin{tabular}{|c|c|c|c|c|c|c|c|c|}
\hline & \multicolumn{2}{|c|}{ Number } & \multicolumn{2}{|c|}{$F E V_{0.75}$ index } & \multicolumn{2}{|l|}{ FVC index } & \multicolumn{2}{|c|}{$F E V_{0.75} / F V C \times 100$} \\
\hline & Boys & Girls & Boys & Girls & Boys & Girls & Boys & Girls \\
\hline \multicolumn{9}{|l|}{ Frequency of infection } \\
\hline None & 776 & 841 & $1.74(0 \cdot 19)$ & $1.67(0 \cdot 20)$ & $1.98(0.22)$ & $1.84(0.22)$ & $87 \cdot 0(6 \cdot 7)$ & $90 \cdot 0(6 \cdot 1)$ \\
\hline Once & 88 & 76 & $1.73(0 \cdot 19)$ & $1.63(0.20)$ & $1.98(0.23)$ & $1.81(0.21)$ & $86.8(6.9)$ & $89 \cdot 2(6 \cdot 9)$ \\
\hline Twice & 30 & 41 & $1.69(0.20)$ & $1.61(0.17)$ & $1.96(0.25)$ & $1.81(0.21)$ & $85.4(8 \cdot 1)$ & $88.4(7.4)$ \\
\hline Thrice & 21 & 20 & $1.69(0 \cdot 19)$ & $1.53(0.29)$ & $2 \cdot 11(0 \cdot 21)$ & $1.71(0.29)$ & $79 \cdot 0(7 \cdot 3)$ & $87 \cdot 3(6 \cdot 6)$ \\
\hline Four times & 20 & 13 & $1.65(0 \cdot 19)$ & $1.56(0.36)$ & $1.92(0.23)$ & $1.77(0.40)$ & $85.0(6.9)$ & $87.6(7.6)$ \\
\hline Five or more times & 55 & 29 & $1.68(0.21)$ & $1.57(0 \cdot 19)$ & $2.01(0.27)$ & $1.76(0.23)$ & $83 \cdot 0(7 \cdot 3)$ & $88 \cdot 3(5 \cdot 5)$ \\
\hline NK or NR & 38 & 32 & $1.75(0.22)$ & $1.67(0.25)$ & $2.05(0.21)$ & $1.80(0.29)$ & $84.7(7 \cdot 8)$ & $92 \cdot 1(5 \cdot 0)$ \\
\hline \multicolumn{9}{|l|}{ Age at first infection } \\
\hline No infection & 774 & 839 & $1 \cdot 74(0 \cdot 19)$ & $1 \cdot 67(0 \cdot 20)$ & $1.98(0.22)$ & $1.84(0 \cdot 22)$ & $87 \cdot 0(6 \cdot 8)$ & $90 \cdot 0(6 \cdot 1)$ \\
\hline Less than 1 year & 93 & 66 & $1.69(0.20)$ & $1.62(0.21)$ & $1.97(0 \cdot 23)$ & $1.80(0 \cdot 22)$ & $85.4(7.6)$ & $89 \cdot 4(7 \cdot 2)$ \\
\hline 1 year & 41 & 38 & $1.72(0.17)$ & $1.62(0.21)$ & $2.04(0.19)$ & $1.84(0 \cdot 26)$ & $83.7(7 \cdot 7)$ & $87 \cdot 2(6 \cdot 7)$ \\
\hline 2 years & 26 & 18 & $1.63(0.26)$ & $1.53(0.31)$ & $1.94(0.37)$ & $1.71(0.31)$ & $83.9(8.8)$ & $87.9(7.4)$ \\
\hline 3 years & 24 & 22 & $1.74(0 \cdot 16)$ & $1.58(0.07)$ & $2.05(0.24)$ & $1.79(0.11)$ & $84 \cdot 7(5 \cdot 8)$ & $87 \cdot 5(5 \cdot 7)$ \\
\hline 4 or more years & 35 & 41 & $1.73(0.21)$ & $1.59(0.25)$ & $2.04(0.20)$ & $1.76(0.26)$ & $83.6(8 \cdot 1)$ & $88.9(7.0)$ \\
\hline NK or NR & 35 & 28 & $1.76(0.22)$ & $1.69(0.26)$ & $2.04(0.20)$ & $1.80(0.30)$ & $86.0(7.0)$ & $92.8(4.9)$ \\
\hline
\end{tabular}

which were all initially tabulated in the form of contingency tables.

Table 1 shows the variables which produced marked and consistent effects on the mean lung function values.

Ethnic origin had a marked effect on the lung function indices, and therefore the analysis of the respiratory morbidity variables was carried out on data from Caucasian children only. Current asthma (one or more episode(s) of asthma during the previous 12 months) had the largest effect on all the lung function indices. The effect of five or more attacks of bronchitis was greater than that of a positive history of winter cough (persistent cough for three months or more during the winter months).

Table 2 shows the different effects of frequency of respiratory infection and age of infection on the lung function indices.

The effect of an increased number of infections produces a generally greater impairment in lung function although the average impairment is not large. By contrast there are no consistent trends in impairment of lung function in respect of the child's age at the first infection.

By the use of the multiple regression analysis allowance is made for the potentially confounding interactions between the independent variables. In table 3 the average deviations from zero in the appropriate independent variables are tabulated in arbitrary units for $\mathrm{FEV}_{0.75} \mathrm{I}$ and $\mathrm{FEV}_{0.75} / \mathrm{FVC}$ (in the case of area of residence there can be no zero or null area for comparison. All comparisons were made with an arbitrarily constructed and hypothetical sixth area). These lung function indices represent those most likely to reflect impairment in lung function. In each column the arbitrary units can be compared between the independent variables but are on a different scale in each of the two lung
Table 3 Summary of results of multiple regression analysis on $F E V_{0 \cdot 75} I$ and $F E V_{0.75} / F V C$

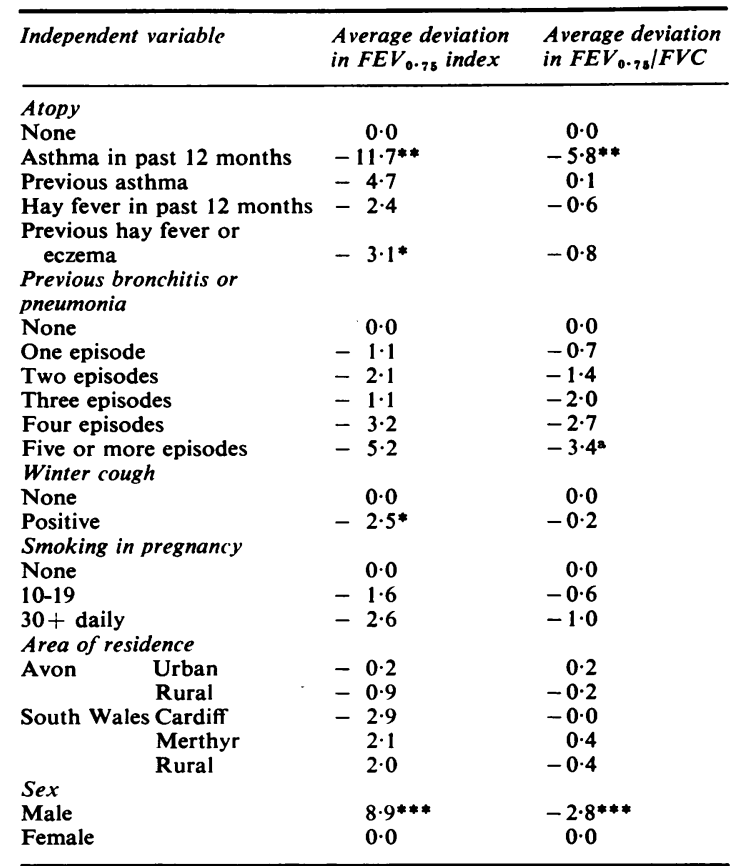

${ }^{*} \mathrm{p}<0.05,{ }^{*} \mathrm{p}<0.01, * * \mathrm{p}<0.001$, a Overall trend $\mathrm{p}<0.05$.

function indices. In the case of these two lung function indices since there were no interactions with sex the effects of each factor are similar for boys and girls. The results presented therefore are those for boys and girls combined.

Current asthmatics showed the largest average deviations from the average values for both lung function indices. Among other atopic manifestations only previous history of hay fever or eczema also 
Table 4 Results of multiple regression analysis on FVCI

\begin{tabular}{|c|c|c|}
\hline \multirow[t]{2}{*}{ Independent variable } & \multicolumn{2}{|c|}{$\begin{array}{l}\text { Average deviation in FVC } \\
\text { index }\end{array}$} \\
\hline & Males & Females \\
\hline \multicolumn{3}{|l|}{ Atopy } \\
\hline None & $0 \cdot 0$ & $0 \cdot 0$ \\
\hline Asthma in previous 12 months & 8.9 & $-50 \cdot 8^{* *}$ \\
\hline Previous asthma & $-4 \cdot 5$ & $-7 \cdot 4$ \\
\hline Hay fever in past year & $-2 \cdot 7$ & 0.0 \\
\hline $\begin{array}{l}\text { Past hay fever or eczema } \\
\text { Area of residence }\end{array}$ & $1 \cdot 2$ & $-12 \cdot 8$ \\
\hline Avon Urban & $\begin{array}{l}-4 \cdot 0 \\
-1 \cdot 1\end{array}$ & $\begin{array}{l}7 \cdot 8 \\
0 \cdot 6\end{array}$ \\
\hline South Wales Cardiff & $-2 \cdot 1$ & $-7 \cdot 7$ \\
\hline Merthyr & $\mathbf{2 \cdot 1}$ & 0.4 \\
\hline Rural & $5 \cdot 1$ & -0.3 \\
\hline $\begin{array}{l}\text { Sex } \\
\text { Difference }\end{array}$ & $18 \cdot 1^{* * *}$ & 0.0 \\
\hline
\end{tabular}

achieved statistical significance (for $\mathrm{FEV}_{0.75} \mathrm{I}$ only).

For previous episodes of bronchitis the trend for frequency of infection did not achieve statistical significance in the case of $\mathrm{FEV}_{0.75} \mathrm{I}$ but for both indices the results were consistent with the hypothesis that repeated infections contributed to larger impairments of lung function. Similar observations may be made for winter cough and smoking in pregnancy but only the change in $\mathrm{FEV}_{0.75} \mathrm{I}$ for winter cough achieved statistical significance. Marked area effects were apparent for FEV $_{\mathbf{0 . 7 5}} \mathrm{I}$ but not for the ratio. Household smoking, maternal and paternal phlegm, and age at infection failed to show any consistent relationship with lung function.

Table 4 shows the effect on FVC I of certain independent variables. Since the regression models indicated that sex interaction was present results are presented for males and females separately.

Only three of the independent variables showed consistent or marked effects on FVC I; atopy, area of residence, and sex. The marked reduction in average FVC I among girls with current asthma is based on only 15 subjects and should be treated with caution.

\section{Discussion}

Other than the effect of ethnic origin on lung function, which has been reported elsewhere, ${ }^{6}$ current asthma had the most marked effect. FEV $_{0.75} \mathrm{I}$ in male asthmatics was reduced on avarge to $92 \%$ of that in non-asthmatics and to $86 \%$ in female asthmatics. Average reductions in the $\mathbf{F E V}_{0.75}$ FVC ratio were to $91 \%$ and $96 \%$ respectively (from table 1). Examination of table 2 indicates that there is a substantial proportion of individuals whose parents reported three or more "significant" respiratory infections. In this study we had followed the pragmatic definition of Tracey ${ }^{7}$ which was ... "bronchitis or pneumonia lasting three or more $\stackrel{5}{\frac{7}{\sigma}}$ days and treated by a doctor." The present data $\frac{\square}{\circ}$ indicate that $10 \%$ of all boys and $6 \%$ of the girls $\frac{\bar{\sigma}}{\bar{N}}$ had such a history. Their average impairment in $\widehat{\nabla}$ FEV $_{0.75} \mathrm{I}$ was $3 \%$ in boys and $7 \%$ in girls; for $\cong$ FEV $_{0.75} /$ FVC ratio the figures were $5 \%$ and $2 \%$ s respectively. These figures are supported by the $\overrightarrow{0}$ data in table 3 in which the effect of previous $\overrightarrow{-}$ infection is examined after allowing for the inde- $\omega$ pendent effects of atopy. One possibility is that children with a history of recurrent infection may $\underset{\omega}{x}$ have had undiagnosed asthma but the prevalence of $\stackrel{\omega}{\%}$ current and all asthma in this study $(3.5 \%$ and $\overrightarrow{ }$ $7.3 \%$ in boys, and $1.5 \%$ and $2.9 \%$ in girls, from table 1) is similar to that found in other surveys. ${ }^{8} 9$ Even so the existence of a relationship between $ㅇ$ "wheezy bronchitis", lung function, and other atopic history (hay fever or eczema) has been demon- $z$ strated in an earlier population study. ${ }^{10}$ But in the $\overbrace{\mathbb{O}}^{\circ}$ present report the effect of any history of atopy on $\exists$ lung function has been taken into account and the independent contribution of an inherited disposition $\vec{\circ}$ to recurrent bronchitis would appear to be small.

The present data are consistent with the hypothesis. that smoking in pregnancy has an independent effect on lung function. ${ }^{11}$ The slope of the regression line did not attain statistical significance but demon- $\bar{O}$ strated a consistent dose-response relationship. Compared to the effect of asthma or recurrent $\stackrel{\Phi}{\complement}$ bronchitis on lung function however the effect was $\overrightarrow{\vec{O}}$ small. Current maternal and total household smoking habit failed to show any independent? relationship to lung function.

\section{References}

${ }^{1}$ Holland WW, Halil T, Bennett AE, Elliott A. Factors influencing the onset of respiratory disease. $\mathrm{Br}$ Med $J$ $1969 ; 2: 205-8$.

2 Colley JRT, Douglas JWB, Reid DD. Respiratory응 disease in young adults: influence of early childhood lower respiratory tract illness, social class, air pollutiono and smoking. Br Med J 1973;3:195-8.

${ }^{3}$ Reid DD. The beginnings of bronchitis. Proc $R$ Soc Med 1969;62:311-6.

4 Yarnell JWG, St Leger AS. Respiratory morbidity and lung function in children in South Wales and the Westos of England. Thorax 1981;36:842-6. 5 Medical Research Council. Respiratory symptoms. London

- Miller GJ, Saunders MJ, Gilson RJC, Ashcroft MT. Lung function of healthy boys and girls in Jamaica in relation to ethnic composition, test exercise performance and habitual physical activity. Thorax 1977;32:486-96.

7 Tracey VV, De NC, Harper JR. Obesity and respiratory ${ }^{+}$ infections in infants and young children. $\mathrm{Br}$ Med 50 1971;1:16-18.

${ }^{8}$ Leeder SR, Corkhill RT, Irwig LM, Holland WW Influence of family factors on asthma and wheezin during the first five years of life. Br J Prev Soc Med 1976 $30: 213-8$ 
- Hamman RF, Halil T, Holland WW. Asthma in schoolchildren: demographic associations and peak expiratory flow rates compared in children with bronchitis. Br J Prev Soc Med 1975;29:228-38.

10 Burr ML, Eldridge BA, Borysiewicz LK. Peak expiratory flow rates before and after exercise in school children. Arch Dis Child 1974;12:923-6.

11 Yarnell JWG, St Leger AS. Respiratory illness, maternal smoking habit and lung function in children. $\mathrm{Br} J \mathrm{Dis}$ Chest 1979;73:230-6. 